these compounds have been carefully studied and their reactivity is similar to that shown by the carbonyl halides, $\mathrm{Mn}(\mathrm{CO})_{5} \mathrm{X}(\mathrm{X}=\mathrm{Cl}, \mathrm{Br}$ or $\mathrm{I})$, suggesting that the $\mathrm{Ph}_{3} \mathrm{PAu}$ group is behaving to some degree like a pseudo-halogen. Other compounds containing $\mathrm{Au}-\mathrm{Co}$ and $\mathrm{Au}$. Fe are also known, e.g., $\mathrm{Ph}_{3} \mathrm{PAuCo}(\mathrm{CO})_{4}$, and $\left(\mathrm{Ph}_{3} \mathrm{PAu}\right)_{2}-\mathrm{Fe}(\mathrm{CO})_{4}$.

An interesting bidentate gold "ligand" has been prepared:

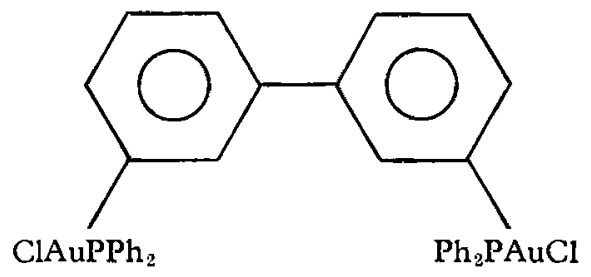

This readily forms complexes with, for example, $\mathrm{H}_{2} \mathrm{Fe}(\mathrm{CO})_{4}$ :<smiles></smiles>

(Organic section omitted for clarity)

Gold also forms stable bonds with main group metals. Triphenylgermyllithium, $\mathrm{Ph}_{3} \mathrm{GeLi}$, reacts with $\mathrm{P}_{3} \mathrm{PAuX}$ compounds to form complexes with
Au-Ge bonds. Corresponding compounds containing $\mathrm{Cu}-\mathrm{Ge}$ and $\mathrm{Ag}-\mathrm{Ge}$ bonds are also known. The stability of the metal-metal bond decreases in the order $\mathrm{Au}-\mathrm{Ge}>\mathrm{Ag}-\mathrm{Ge}>\mathrm{Cu}-\mathrm{Ge}$.

Several polynuclear compounds containing gold aggregates have been reported. In general they are prepared by the reduction of suitable phosphine-gold halide complexes with sodium borohydride, e.g.,

$$
\mathrm{Ph}_{3} \mathrm{PAuCl} \frac{\mathrm{NaBH}_{4}}{\mathrm{H}_{2} \mathrm{O}} \rightarrow \text { " } \mathrm{Au}_{5}\left(\mathrm{Ph}_{3} \mathrm{P}\right)_{4} \mathrm{Cl} "
$$

Initial work suggested structures based on three, five, and six gold atoms but later X-ray studies indicated that a number of these complexes may be much more complex. A triphenylphosphine complex which, on the basis of analytical data, was believed to be $\mathrm{Au}_{6} \mathrm{~L}_{6}(\mathrm{CNS})_{2}$ has now been recognised as $\mathrm{Au}_{11} \mathrm{~L}_{7}(\mathrm{SCN})_{3}$. A central gold atom is surrounded by ten remaining gold atoms each of which has one ligand attached to it. The structure is best described approximately as a combination, by apex sharing, of a pentagonal bipyramid and square pyramid with gold atoms at all vertices. Clusters containing ten, twelve, and thirteen gold atoms have been predicted.

\section{Conclusion}

The chemistry of gold is virtually unexplored. Two main areas worthy of current interest are the preparation of organo-gold compounds and of compounds containing gold-metal or gold-gold bonds. Indeed, preliminary data at present available on other related systems have shown that such compounds have pronounced catalytic activity.

\title{
Gold Alloys for Cardiac Pacemakers
}

\section{ELECTROCATALYSTS IN BODY IMPLANTABLE FUEL CELLS}

The technique of cardiac pacemaking is now firmly established, and it is estimated that in the United States alone there are 50,000 patients carrying permanently implanted pacemakers. Problems of longevity of the mercury-zinc cell normally used as a source of power are, however, giving concern and efforts are being directed towards the use of either nuclear power or of a fuel cell to promote longer life.

At the Fall Meeting of the Electrochemical Society in Atlantic City a number of papers dealt with this subject, particularly with the idea of utilising the oxidising and reducing substances normally found in the blood stream both as reactants and as electrolyte in an implantable fuel cell. This concept requires selective electrocatalysts for hydrocarbon oxidation at the anode and for oxygen reduction at the cathode, and several groups of workers are at present exploring this field.
One paper, by J. H. Fishman and J. F. Henry of Leesona Moos Laboratories, reported a study of alloys in the gold-palladium system which they had found to satisfy the selectivity requirement in tests with simulated and natural blood. Significant transitions in the bulk properties of these alloys occur in the 35 and the 60 atomic per cent gold regions, and it was found that their catalytic properties similarly undergo transitions in the same composition regions. The gold-palladium system thus gives a remarkable spectrum of electrocatalytic properties, some alloys being substantially selective for the anodic process while others are selective for the cathodic process in a dissolved mixture of oxygen and oxidisable hydrocarbons.

The authors were successful in deriving electric power with such oppositely selective electrodes from flowing oxygenated human blood. 